\title{
Exosomes in hepatocellular carcinoma: a new horizon
}

\author{
Rui Chen ${ }^{1}$, Xin Xu', Yuquan Tao ${ }^{1}$, Zijun Qian ${ }^{1}$ and Yongchun $Y u^{1,2^{*}}$
}

\begin{abstract}
Exosomes are a class of extracellular vesicles released by multiple cells types including tumor cells, with a size range of 30-100 nm and a lipid bilayer membrane. Recently, the role of exosomes in cell-to-cell communication has been extensively studied, showed that exosomes can deliver their functional RNAs and proteins to recipient cells, impacting transcription and translation of recipient cells. Emerging evidence suggests that hepatocellular carcinoma (HCC) cellderived exosomes can construct a fertile environment to support HCC cells proliferation, grow, invasion and metastasis, development of drug resistance. Circulating exosomes can be used as noninvasive biomarkers for early diagnosis, moreover as drug delivery vehicles, provide new insights into the treatment of HCC.
\end{abstract}

Keywords: Hepatocellular carcinoma, Exosomes, Biomarkers, Therapy

\section{Background}

Liver cancer is the sixth most common cancer and the fourth leading cause of cancer-related deaths worldwide in 2018, with approximately 841,000 new cases and 782,000 deaths annually [1]. Hepatocellular carcinoma (HCC) is the most primary malignant liver tumors, and linked to hepatitis B or hepatitis C infection as well as cirrhosis [2]. Although great advancement has been achieved in diagnosis and therapeutic strategies, such as hepatic resection, liver transplantation, ablative therapy, chemoembolization, and sorafinib, the long-term survival remains daunting, owing to high rate of metastasis and relapse [3].

Exosome, a nanosized membrane vesicle, contains nucleic acids, proteins, and lipids. Surprisingly, exosomes are not only specifically target to the membrane proteins of host cells to initiate downstream signaling, but are also able to deliver genetic cargos into the cytoplasm, which provide novel mechanisms of intercellular communication. Similarly, in cancer, exosomes act as vehicles for exchange of cargos between heterogeneous populations of tumor cells and neighbor cells as well as distant cells, reprogramming tumor environment. In a review, we summarize the recent findings regarding

\footnotetext{
* Correspondence: yuyongchun1255@126.com

1Shanghai Municipal Hospital of Traditional Chinese Medicine, Shanghai University of Traditional Chinese Medicine, Shanghai 200071, China

${ }^{2}$ Shanghai Chest Hospital, Shanghai Jiao Tong University, 241 Huaihai West Road, Shanghai 200030, China
}

HCC cell-derived exosomes, contribute to elucidate the molecular mechanisms underlying HCC progression and may provide a novel diagnosis and therapy strategy of HCC.

\section{Exosomes biogenesis}

Exosomes are small membrane vesicles with a size of

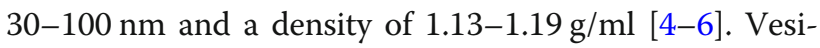
cles released from sheep reticulocytes during maturation were first termed exosomes by Johnstone et al. in 1987 [7]. The generation of exosomes by inward budding of the plasma membrane to form early endosomes, further inward budding of the limiting membrane inside endosome generate intraluminal vesicles (ILVs), bodies (MVBs) can either fuse with the plasma membrane, releasing of the vesicles into the extracellular space in the form of exosomes, or, alternatively, traffic to lysosomes, degrading of vesicular contents (Fig. 1) [8-11].

Endosomal sorting complexes required for transport (ESCRT), multiprotein complexes consisted of ESCRT -0, -I, -II, and -III, as well as accessory proteins (VPS4, VTA1 and ALIX), are involved in intraluminal vesicles formation and cargos sorting [12-14]. The ESCRT-0, which composes of HRS/Vps27p and STAM, is essential for initial selection of ubiquitylated cargos at the endosomal membrane, ubiquitylated cargos are first recognized by HRS, then transfer to ESCRT-I and ESCRT-II, which are responsible for membrane deformation into 


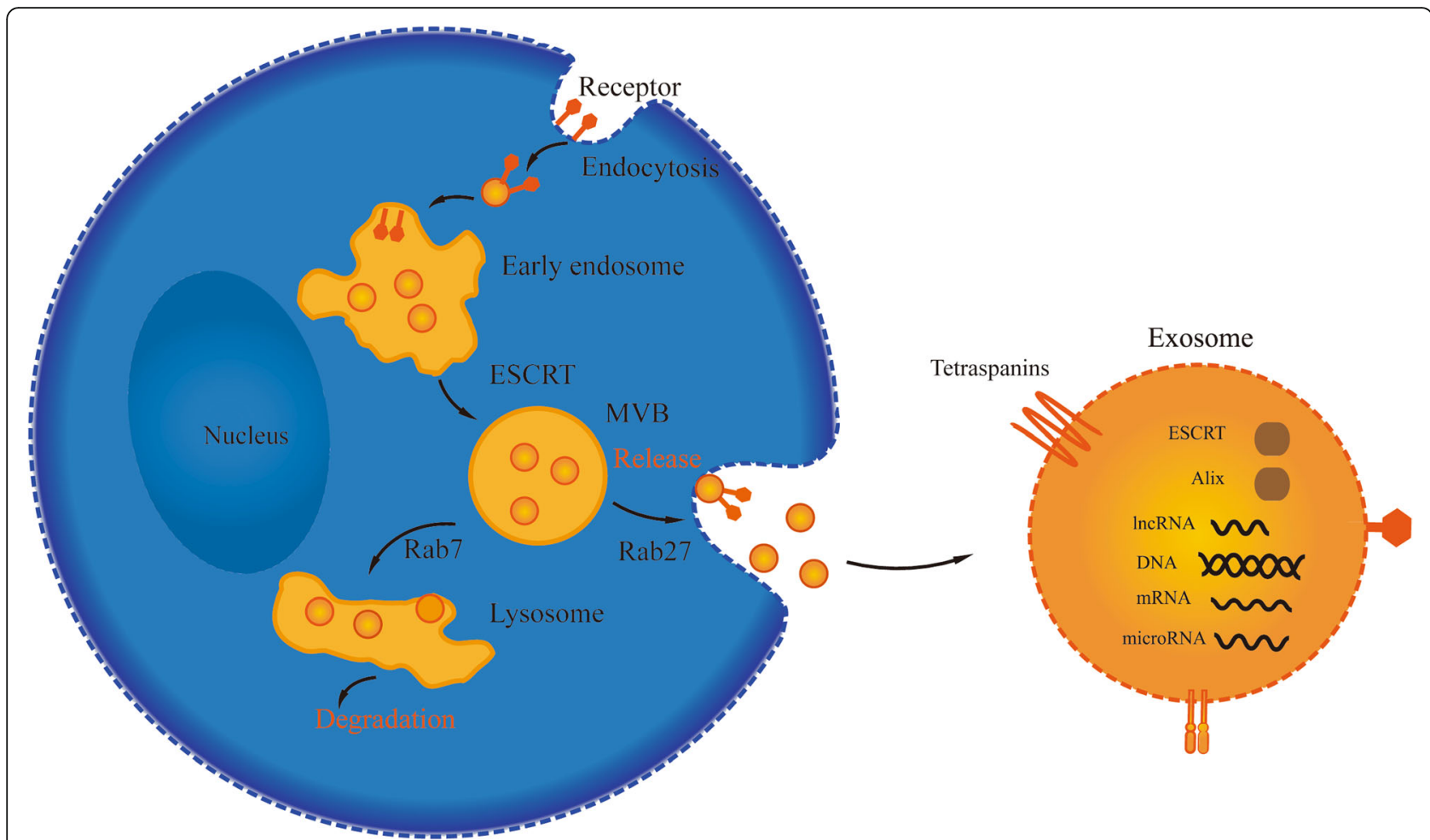

Fig. 1 Exosomes biogenesis. Exosomes are vesicles of endocytic origin, following inward budding of the plasma membrane to form early endosomes, further inward budding of the multivesicular bodies (MVBs) generate intraluminal vesicles (ILVs), MVBs fuse with the plasma membrane, and release exosomes into the extracellular space. ESCRT and ESCRT-independent mechanism involved in exosomes biogenesis and release

buds with sequestered cargos, subsequently activate ESCRT-III and the accessory proteins VPS4 ATPase, drive vesicles scission to form intraluminal vesicles. After scission, cargos are internalized in intraluminal vesicles whereas ESCRT-III remains on the outside of the membrane until it is recycled by Vps4 [15-19].

However, an ESCRT-independent mechanism involved in exosomes biogenesis and release has also been demonstrated. For example, the sphingolipid ceramide enrich in exosome, and the release of exosomes was reduced after the inhibition of neutral sphingomyelinases [20]. There are evidences showing that Rab5, Rab7, Rab27a and Rab27b of the Rab family of small GTPases participate in multivesicular endosomes trafficking and fusion with the plasma membrane or lysosome [21-23]. In addition, the tetraspanin proteins such as CD9, CD63, and CD81 have also been found to function in MVB trafficking and exosome secretion [24, 25].

\section{Exosomes compositon}

Exosomes are released into the extracellular space by multiple cell types, including hematopoietic cells, immune cells, intestinal epithelial cells, neurons, fibroblasts, mesenchymal stem cells and tumor cells [26-28]. Owing to their endocytic origin, exosomes can fuse with membrane of recipient cells and deliver their contents into the cytoplasm [29]. Or, exosomes were internalized by recipient cells through clathrin-independent and clathrin-mediated endocytosis, such as phagocytosis, macropinocytosis and pinocytosis [30-32]. In addition, membrane proteins of the exosomes can engage the receptors of recipient cells to induce intracellular signaling [33].Therefore, the composition of exosomes are crucial determining factors in their effects.

The lipids composition of exosomes are differences with whole cell membranes, which are enriched in cholesterol, sphingomyelin, ceramide and phosphatidylserine, and generally of saturated fatty acids, while lysobisphosphatidic acid (LBPA), a lipid described in intraluminal vesicles, was not enriched [34-36].

Initial proteomic studies revealed that exosomes contain a particular subset of proteins from endosomes, the plasma membrane and the cytosol, but very little from nucleus, mitochondria, endoplasmic reticulum, and the Golgi complex [37]. Exosomes from different cell types contain membrane transport and fusion proteins (GTPases, annexins and flotillin), tetraspanins (CD63, CD9, CD81 and CD82), the ESCRT complex (TSG101, Alix), and heat shock proteins (HSP60, HSP70 and HSP90) [38-41], notably, these membrane proteins are usually used as markers for exosome identification. Except for these proteins, exosomes also include some 
specific proteins reflective of their parental cells, for example, integrins ( $\alpha v \beta 5, \alpha 6 \beta 4$ and $\alpha 6 \beta 1)$ [42], MHC class I and II molecules, FasL, tumour-necrosis-factor-related apoptosis-inducing ligand (TRAIL) or programmed-cell death ligand 1(PD-L1) and prostaglandin E2 [43], as well as epidermal growth factor receptor (EGFR) [44, 45], these membrane proteins mediate interaction with specific receptors on target cells, triggering downstream signalling events.

The first identified of mRNA and microRNA in exosomes were secreted by mast cells, and in vitro translation proved that the transferred exosomal mRNA can be translated into proteins after entering recipient cell [46]. Exosomes show selectivity in their RNAs loading compared to the cells, RNAs transported by exosomes are mostly small RNA (<200 nucleotides) and fragmented mRNAs [47]. Exosomes transfer miRNAs to recipient cells, then miRNA target mRNA that regulate proteins translation involved in a wide range of biological processes $[48,49]$. Apart from mRNA and miRNA, other RNAs were also identified in exosomes containing long noncoding RNA (lncRNA), transfer RNA (tRNA), ribosomal RNA (rRNA), small nucleolar RNA (snoRNA), small nuclear RNA (snRNA), small cytoplasmic RNA, silencing RNA and piwi-interacting RNA [50-53]. They are predominately fragmented mRNAs, microRNAs, and lncRNAs by exosomes transferred to recipient cells and functional in this new location, thereby impacting the transcriptome of recipient cells [54]. Noteworthy, exosomes-enclosed RNAs are protected against RNase degradation, making them ideal circulating biomarkers [55]. In additon, Balaj et al. investigated that exosomes include singlestranded DNA, containing both cDNA and genomic, as well as high levels of retrotransposons sequences [56]. There are studies indicate that exosomes also carry large fragments of double-stranded genomic DNA, encompassing all chromosomes $[57,58]$.

\section{Isolation of exosomes}

The isolation of exosomes from cell culture supernatants or other bodily fluids is critical to analysis function of exosomes. Ultracentrifugation is the most widely used conventional approach for exosomes isolation [59-65]. To avoid contamination by serum exosomes, conditioned culture media was replaced by serum-free medium [64, 65], or, fetal bovine serum (FBS) previously depleted of exosomes [66-68]. In brief, exosomes were isolated by successive centrifugations at $300 \times \mathrm{g}$ for $5 \mathrm{~min}$, $2000 \times \mathrm{g}$ for $10 \mathrm{~min}$, and $10,000 \times \mathrm{g}$ for $30 \mathrm{~min}$ to eliminate cells, dead cells, and cellular debris, $100,000 \times \mathrm{g}$ for 70 min to collect exosomes fractions. The exosome pellets were washed in a large volume of PBS to eliminate contaminating proteins, and centrifuged one last time at
$100,000 \times \mathrm{g}$ for $70 \mathrm{~min}$. Of note, all centrifugations were performed at $4{ }^{\circ} \mathrm{C}$ [59]. In some cases, the supernatant was filtered through a $0.22-\mathrm{mm}$ filter to eliminate any remaining debris for further purification by ultracentrifugation [59, 67]. Although ultracentrifugation is most widely used gold standard for exosomes isolation, however, the method has some limitations, for example, successive centrifugations steps resulting in low yield and low recovery, as well as low purity that may contain aggregated proteins and ribonuclear protein particles [69]. Sucrose-gradient centrifugation is also commonly used isolation methods of exosomes, which extra use a sucrose cushion to eliminate more contaminants and further fractionate different vesicular density [59, 70-72]. Sucrose-gradient centrifugation is considered to isolate exosomes at a higher purity, especially greater purity and quantity mRNA profile $[73,74]$. The immuno-magnetic isolation of exosomes is a versatile and rapid method for the analysis of membrane proteins of exosomes [75, 76]. However, this method is not intended for large sample volumes, and trapped exosomes may not retain full functionality even though successfully eluted from the beads surface [59]. Tauro BJ et al. discovered exosomes-specific markers abundance in LIM1863 colorectal cancer cells isolated by three different methods. They found antibody-coated magnetic beads to be the most effective methods for isolation of exosomes compare to ultracentrifugation and density gradient separation [77]. Additionally, exosomes are also isolated by using commercially available reagent, for instance, ExoQuick (System Biosciences) is the most commonly used reagent that base on polymer coprecipitation protocols $[65,66]$.The ExoQuick reagents precipitate exosomes by decrease the solubility, which is easy and user-friendly method, but lack specificity and may cause heterogeneous polymeric particles [78]. Caradec J et al. used two different methods to isolate exosomes form serum sample, and indicated that ExoQuick ${ }^{\text {Tw }}$ is an efficient and reproducible approach for exosomes quantitative studies compare to ultracentrifugation [79]. The isolation of exosomes from blood is crucial to develop exosomes as biomarkers of HCC. Plasma is a highly complex and viscous fluid with a protein concentration of $60-80 \mathrm{mg} / \mathrm{ml}$ [80]. Owing to the viscosity of plasma, it is essential to dilute plasma, and increase the speed and lengths of centrifugations [59].

However, after the isolation of exosomes, it is necessary to further identify the exosome morphology, size and marker. Exosomes exhibite typical cup-shaped morphology under transmission electron microscopy (TEM), and nanoparticle tracking analysis (NTA) the size distributions and number of exosomes, as well as western blotting identify the exosomes marker, such as TSG101,CD63 [81-83]. 


\section{Functions of exosomes in HCC}

Exosomes contain specific microRNA, IncRNA and proteins that derive from the parental cells, indeed, cancer-derived exosomes can reflect the characteristics of the tumors. Most notably, exosomes can easily be obtained from a multitude of biological fluids of cancer patients, such as saliva, breast milk [84], cerebral spinal fluid [85], serum and plasma [86], urine [87], ascites [88], pleural effusions [89] and bronchoalveolar lavage fluid [90]. Furthermore, exosomes are very stable for long time storage at $-80^{\circ} \mathrm{C}$, thus, exosomes can be used as a promising biomarkers for cancer diagnosing and dynamical monitoring $[4,6,91,92]$.

Of note, tumor-derived exosomes carry a functional molecular cargo and trigger various autocrine and paracrine signaling cascades that induce malignant transformation and field cancerization. Increasing evidence showing that exosome play a significant role in tumorigenesis, growth, progression, metastasis, immune escape and drug resistance as well as treatment of cancer $[4,6$, 91-95]. With the rapid development of exosomes research has helped to reveal novel mechanisms underlying HCC initiation and progression, and demonstrate that exosomes are critical intercellular messengers employed by HCC cells to architect the local and distant microenvironment.

\section{Exosomes as potential biomarkers for HCC}

Several studies suggested that serum exosomes and their mRNA, microRNA, as well as lncRNA might serve as biomarkers for HCC screening and monitoring (Table 1).

$m R N A$ in HCC exosome The serum exosomal heterogeneous nuclear ribonucleoprotein H1 (hnRNPH1) mRNA levels in HCC patients were remarkably higher than chronic hepatitis B patients, besides, which were associated with the portal vein tumor emboli, lymph node metastasis, Child-Pugh classification, TNM stage and overall survival [96].

microRNA in HCC exosome Serum exosomal miR-718 expression was significantly lower in HCC patients with larger tumour diameters and recurrence after liver transplantation [97]. The expression level of serum exosomal

Table 1 Serum exosomal-derived biomarker studies in HCC

\begin{tabular}{|c|c|c|c|c|}
\hline Biomarkers (expression) & Method & Cohort (patients) & Clinical significance & References \\
\hline \multicolumn{5}{|l|}{ (1) mRNA } \\
\hline $\begin{array}{l}\text { hn-RNPH1 } \\
\text { mRNA } \uparrow\end{array}$ & Taqman real-time PCR & $\begin{array}{l}68 \text { HCC vs } 67 \text { LC vs } 68 \text { CHB } \\
\text { vs } 68 \text { healthy control }\end{array}$ & $\begin{array}{l}\text { Diagnostic biomarker for dividing } \\
\mathrm{HCC} \text { and } \mathrm{CHB}\end{array}$ & [96] \\
\hline \multicolumn{5}{|l|}{ (2) miRNA } \\
\hline 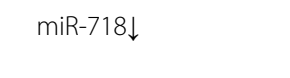 & qRT-PCR & $59 \mathrm{HCC}$ & $\begin{array}{l}\text { Predicting biomarker for recurrence } \\
\text { afer } \mathrm{LT}\end{array}$ & [97] \\
\hline $\begin{array}{l}\operatorname{miR}-18 a \uparrow \\
\operatorname{miR}-221 \uparrow \\
\operatorname{miR}-222 \uparrow \\
\operatorname{miR}-224 \uparrow\end{array}$ & qRT-PCR & $\begin{array}{l}30 \text { HCC vs } 30 \text { CHB vs } 30 \\
\text { healthy controls }\end{array}$ & $\begin{array}{l}\text { Diagnostic biomarker for dividing } \\
\mathrm{HCC} \text { and } \mathrm{CHB}\end{array}$ & [99] \\
\hline $\begin{array}{l}\text { miR-101 } \downarrow \\
\text { miR-106b } \downarrow \\
\text { miR-122 } \\
\text { miR-195 }\end{array}$ & qRT-PCR & $20 \mathrm{HCC}$ vs 20 CHB vs 20 LC & $\begin{array}{l}\text { Diagnostic biomarker for dividing } \\
\mathrm{HCC} \text { and CHB }\end{array}$ & [99] \\
\hline MiR-125b $\uparrow$ & qRT-PCR & 158 HCC vs 30 CHB vs 30 LC & $\begin{array}{l}\text { Predicting biomarker for recurrence } \\
\text { and survival }\end{array}$ & [100] \\
\hline $\begin{array}{l}\operatorname{miR}-122 \uparrow \\
\operatorname{miR}-148 \mathrm{a} \uparrow \\
\mathrm{miR}-124 \mathrm{~b} \uparrow\end{array}$ & qPCR & 5 HCC vs 5 LC & $\begin{array}{l}\text { Diagnostic biomarker for dividing } \\
\text { HCC and LC }\end{array}$ & [101] \\
\hline $\begin{array}{l}\operatorname{miR}-122 \uparrow \\
\operatorname{miR}-148 \mathrm{a} \uparrow \\
\mathrm{AFP} \uparrow\end{array}$ & qPCR & 5 HCC vs 5 LC & $\begin{array}{l}\text { Diagnostic biomarker for dividing } \\
\text { HCC and LC }\end{array}$ & [101] \\
\hline $\operatorname{miR}-122 \uparrow$ & qPCR & 5 HCC vs 5 LC & $\begin{array}{l}\text { Diagnostic biomarker for dividing } \\
\text { HCC and healthy }\end{array}$ & [101] \\
\hline \multicolumn{5}{|l|}{ (3) IncRNA } \\
\hline InCRNA-HEIH $\uparrow$ & qRT-PCR & $\begin{array}{l}35 \text { HCC vs HCV-induced } \\
\text { Cirrhosis vs } 10 \text { HCV-induced } \\
\text { HCC }\end{array}$ & $\begin{array}{l}\text { Diagnostic biomarker for dividing } \\
\text { HCC and CHC }\end{array}$ & [102] \\
\hline 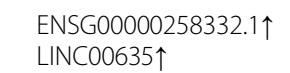 & $\begin{array}{l}\text { Taqman } \\
\text { PCR }\end{array}$ & $\begin{array}{l}60 \text { HCC vs } 85 \text { LC vs } 96 \text { CHB } \\
\text { vs } 60 \text { healthy subjects }\end{array}$ & $\begin{array}{l}\text { Diagnostic biomarker for dividing } \\
\text { HCC and CHB and LC }\end{array}$ & [103] \\
\hline
\end{tabular}

CHC chronic hepatitis $C, C H B$ chronic hepatitis $B, H C V$ hepatitis $C$ virus, $L C$ liver cirrhosis, $L T$ liver transolantation, $q R T-P C R$ quantitative reverse transcription polymerase chain reaction, $Q P C R$ quantitative polymerase chain reaction, AFP alpha-fetoprotein 
miR-21 was markedly higher in patients with HCC than those with chronic hepatitis B, and its expression correlated with cirrhosis and advanced tumor stage [98]. The serum exosomal miR-18a, miR-221, miR-222 and miR-224, as well as miR-125b were remarkably higher in HCC patients than chronic hepatitis B patients and liver cirrhosis patients $[99,100]$. In addition, the serum exosomal miR-101, miR-106b, miR-122 and miR-195 were lower in HCC patients than chronic hepatitis B patients [99]. The levels of serum exosomal miR-122, miR-148a, and miR-124b were markedly higher in HCC than liver cirrhosis, but not different from chronic hepatitis. Furthermore, Serum exosomal miR-122, miR-148a combined with alpha-fetoprotein (AFP) were significantly distinguish early HCC from liver cirrhosis, additionally, miR-122 was the best for differentiating HCC from healthy subjects [101].

lncRNA in HCC exosomes Serum exosomal lncRNAHEIH in hepatitis $C$ virus-related HCC patients was remarkably higher than those patients with hepatitis C virus-induced cirrhosis [102]. The levels of serum exosomal lncRNAs ENSG00000258332.1 and LINC00635 in the HCC patients were significantly higher than those in liver cirrhosis, chronic hepatitis B patients and healthy subjects. A high ENSG00000258332.1 or LINC00635 level in HCC was related to lymph node metastasis, TNM stage and overall survival. In addition, a high ENSG00000258332.1 level was associated with portal vein tumor emboli. Furthermore, the combination of the 2 lncRNAs and AFP were remarkably higher sensitivity and specificity than AFP in identifying HCC from chronic hepatitis B [103].

\section{Exosomes and hepatocarcinogenesis}

Emerging evidence suggests that HCC cell-derived exosomes mediated interaction between HCC cells and their surrounding microenvironment, educating normal cells turn into tumor cells. For example, HCC cell-derived exosomes delivered a functional miRNA to recipient cells, which modulated transforming growth factor $\beta$ activated kinase-1(TAK1) expression and downstream signaling c-Jun NH2-terminal kinase (JNK)/p38 MAPK and nuclear factor (NF)- $\mathrm{\kappa B}$ in recipient cells, thus facilitating tumorigenesis in the liver [104]. HCC cell-derived exosomes were actively internalized by adjacent adipocytes, and induced inflammatory cytokines secretion, meanwhile, activated various kinases and NF- $\mathrm{kB}$ signaling pathway in adipocytes, strongly supporting tumor growth and progression [105]. HCC-derived exosomes transferred their pro-tumorigenic RNAs and proteins to normal hepatocyte, which triggered PI3K/AKT and MAPK signaling pathways in host cells, moreover, increased secretion of metalloproteinases MMP-2 and
MMP-9, hence facilitating tumorigenesis in normal hepatocytes [106].

\section{Exosomes in $\mathrm{HCC}$ angiogenesis}

Likewise, recently reported that HCC cells-derived exosomes can transfer their biologically active lncRNAs and proteins to endothelial cells within their microenvironment, and induced the tube-like structures formation in endothelial cells, promoting angiogenesis. Cancer stemcell-like CD90+ liver cells-derived exosomes transferred IncRNA H19 to human umbilical vein endothelial cells (HUVECs), which markedly increased the transcripts of VEGF, the most powerful pro-angiogenic cytokine, and upregulated the VEGF production and release, furthermore, induced the tube-like structures formation in endothelial cells, promoting angiogenesis [107]. In addition, vasorin, a type I transmembrane protein, was released and transferred from HCC cells to HUVECs by exosomes, and promoted angiogenesis [108].

\section{Exosomes and epithelial-mesenchymal transition}

Epithelial-mesenchymal-transition (EMT) is a process whereby epithelial cells lose their characteristics and acquisition of the mesenchymal phenotype [109]. It is clear that EMT play a critical role in cancer progression and malignant transformation by inducing the loss of cell-cell adhesion to promote tumor cells invasion and metastasis [110].

Accumulating evidences indicated that tumor-derived exosomes carry functional molecules that activated mesenchymal-associated gene expression and induced diverse signalling in recipient cells, thereby promoting EMT and premetastatic niche formation [93, 111]. Chen et al. investigated the role of $\mathrm{HCC}$ cell-derived exosomes in EMT. Highly metastatic MHCC97-H cells secreted exosomes were taken up by low metastatic HLE cells, subsequently, the high expression of mesenchymal markers, such as $\alpha$-SMA, N-cadherin and vimentin, as well as the low expression of epithelial marker E-cadherin were observed in HLE cells. Moreover, the levels of EMT promoters (Slug, ZEB1 and ZEB2) were increased, in contrast, the level of mesenchymal-epithelial transition (MET)-driving promoter OVOL1 was decreased in HLE cells. Further found that MAPK/ERK signalling was activated in host HLE cells, thereby undergoing epithelialmesenchymal transition (EMT), and promoting migration, chemotaxis and invasion of the host HCC cells [112].

\section{Exosomes and cancer-associated fibroblasts}

In tumor microenvironment, cancer-associated fibroblasts (CAFs) actively participated in the synthesis, deposition and remodelling of much of the extracellular matrix in tumor stroma, and they are regard as a source of paracrine growth factors that impact the growth of 
Table 2 Exosomal cargos detected in HCC and their target and clinical relevance

\begin{tabular}{|c|c|c|c|}
\hline Exosomal cargos & Target & Biological/clinical relevance & Reference \\
\hline \multicolumn{4}{|l|}{ (1) miRNA } \\
\hline miRNA & TAK1 & Facilitated tumorigenesis & [104] \\
\hline miR-1247-3p & B4GALT3 & Converted normal fibroblasts to cancer-associated fibroblasts (CAFs) & [114] \\
\hline miR-122 & & Suppressed HCC cells growth and proliferation & [115] \\
\hline miR-320a & PBX3 & Suppressed CAFs proliferation & [118] \\
\hline miR-335-5p & & Inhibited HCC cells proliferation & [119] \\
\hline miR451,miR223, miR24,miR125b miR31,and miR122 & & Inhibited HCC cells growth and stimulated apoptosis & [120] \\
\hline miR-103 & & Facilitated tumor metastasis & [122] \\
\hline miR-32-5p & PTEN & Induced multidrug resistance in Bel7402 cells & [131] \\
\hline \multicolumn{4}{|l|}{ (2) IncRNA } \\
\hline IncRNA H19 & & Promoted angiogenesis & [109] \\
\hline TUC339 & & Promoted HCC proliferation and spread & [116] \\
\hline linc-RoR & miR-145 & Increased HCC cells viability and promoted HCC cells survival & [117] \\
\hline InCRNA FAL1 & miR-1236 & Promoted Huh7 and HepG2 cells proliferation and metastasis & [123] \\
\hline linc-VLDLR & ABCG2 & Leaded to acquired chemoresistance in HCC cells & [133] \\
\hline \multicolumn{4}{|l|}{ (3) Proteins } \\
\hline proteins & & Facilitated tumorigenesis in normal hepatocytes & [106] \\
\hline Vasorin & & Promoted angiogenesis & [108] \\
\hline
\end{tabular}

TAK1 transforming growth factorßactivated kinase-1, B4GALT3 $\beta$-1,4-galactosyltransferases, PTEN phosphatase and tensin homolog, PBX3 pre-B-cell leukemia transcription factor 3, ABCG2 ATP-binding cassette, sub-family $\mathrm{G}$ member 2

cancer cells [113], yet, in which tumor-derived exosomes may play a crosstalk role. Recently, Fang et al. showed that HCC cells-derived exosomes delivered miR-1247-3p to normal fibroblasts, miR-1247-3p directly targeted $\beta$-1,4-galactosyltransferases (B4GALT3), a protein mediating glycosylation, with the subsequent activation of $\beta 1$-integrin-NF- $\mathrm{kB}$ signaling in fibroblasts, normal fibroblasts converted to cancer-associated fibroblasts (CAFs). Furthermore, activated CAFs secreted pro-inflammatory cytokines, such as IL-6 and IL-8, consequently promoting HCC progression and metastasis [114].

\section{Exosomes regulate $\mathrm{HCC}$ growth and progression}

Of note, many studies have shown that exosomes act as vehicles for exchanged their microRNA or IncRNA between HCC cells and/or different types of cells in the tumour microenvironment, regulating $\mathrm{HCC}$ growth and progression. HCC cell Huh7-derived exosomes released miR-122 that was taken up by recipient HepG2 cells, interestingly, which effectively suppressed the recipient HepG2 cells growth and proliferation [115]. HCC cell-derived exosomes transferred ultraconserved lncRNA TUC339 to neighbour cells within the microenvironment, TUC339 were transcribed in host cells, promoting HCC proliferation and spread [116]. Under hypoxia, a long intergenic noncoding RNA regulator of reprogramming (linc-RoR) expression was highly increased in HCC cells, most importantly, HCC cells-derived exosomes shuttled
linc-RoR between tumors cells, linc-RoR increased HCC cells viability and promoted HCC cells survival by modulated the miR-145-HIF-1a signaling [117]. HCC patients paracancer fibroblasts-derived exosomes transferred miR-320a to cancer-associated fibroblasts (CAFs) from HCC patients, in particular, miR-320a repressed its direct downstream target PBX3, simultaneously suppressed the activation of the MAPK pathway, further suppressed CAFs proliferation [118]. Liver fibroblasts-derived exosomes delivered miR-335-5p to HCC cells, which finally inhibited HCC cells proliferation [119]. Human adult liver stem cells (HLSC)-derived exosomes contain a few miRNAs with potential antitumor activity, such as miR-451, miR-223, miR-24, miR-125b, miR-31 and miR-122. Notably, HLSCs-derived exosomes transferred those miRNAs to HCC cells, which significantly inhibited growth and stimulated apoptosis of host HCC cells [120].

\section{Exosomes and HCC metastasis}

It is well known that intrahepatic and distal metastasis is the pivotal cause of poor prognosis of $\mathrm{HCC}$, whereas exosomes widely participate in this process. High motile ability of MHCC97-H cells delivered exosomes to low motile ability of MHCC97-L cells, which increased the expression of adenylyl cyclase-associated protein 1, and promoted HCC metastasis [121]. HCC cell-derived exosomes delivered miR-103 into endothelial cells, then miR-103 inhibited the expression of zonula occludens 1 , 


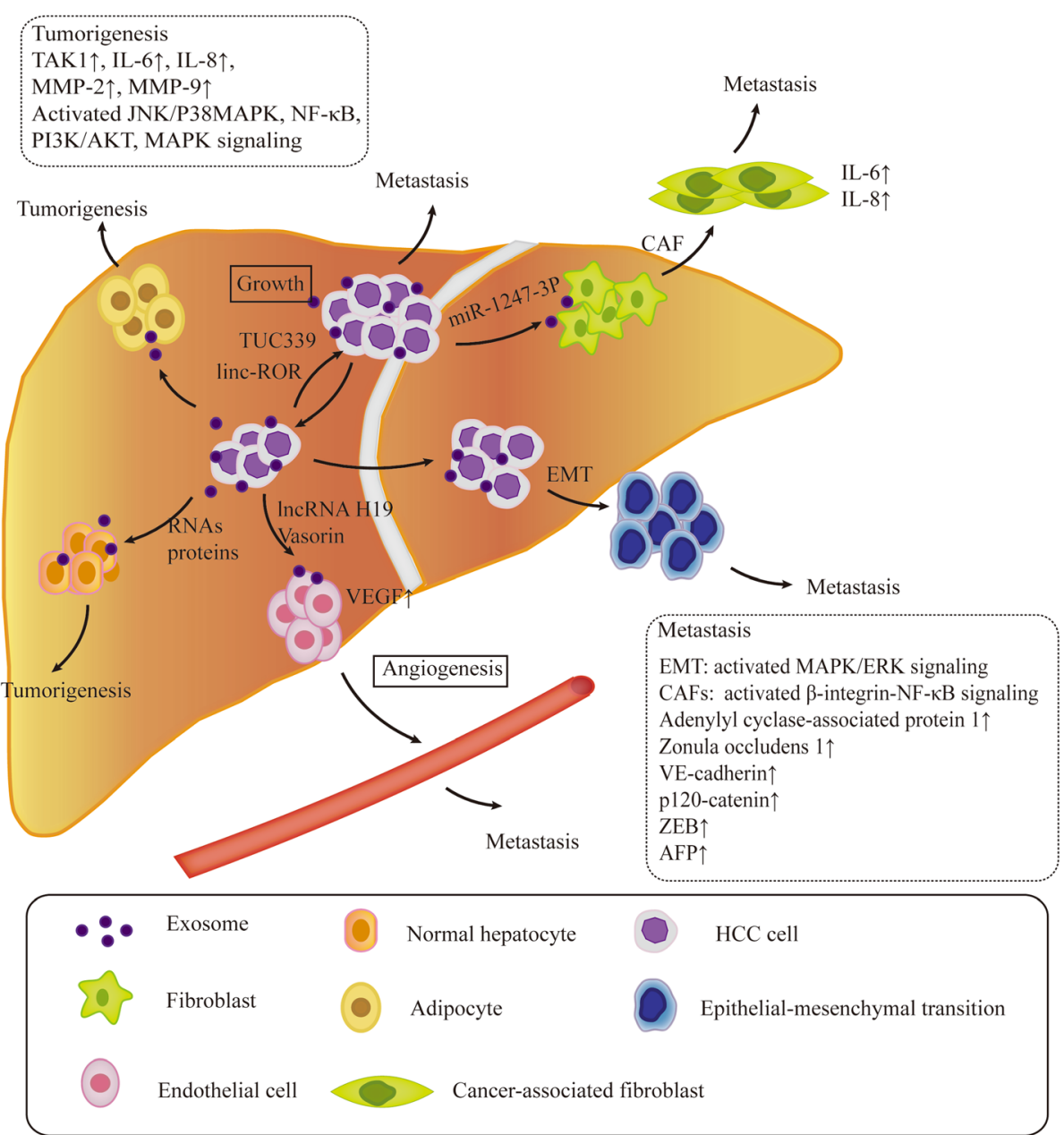

Fig. 2 Functions of exosomes in HCC. Exosomes play a significant role in mediating interaction between HCC cells and their surrounding microenvironment. HCC cells-derived exosomes transferred their biologically active RANs and proteins to recipient cells, and triggered various signaling in recipient cells, facilitating tumorigenesis, angiogenesis, HCC cells growth and metastasis

VE-cadherin, and p120-catenin in endothelial cells, which attenuated endothelial junction integrity and consequently increased vascular permeability and facilitated tumor metastasis [122]. Exosomes from the serum of HCC patients transmitted lncRNA FAL1 to target Huh7 and HepG2 cells, lncRNA FAL1 competitively bound to miR-1236 of target cells, and up-regulated the ZEB1 and AFP expression, thus promoting target cells proliferation and metastasis [123].

\section{Function of exosomes in HCC therapies Exosomes and immunotherapy of HCC}

In recent years, the exosome-based cancer therapeutics has been extensively explored, revealed that the potential role of tumor-derived exosomes (TEX) and dendritic cell-derived exosomes (DEX) in cancer immunotherapy [94]. Wolfers J et al. found that TEXs transferred tumor antigens to dendritic cells, ultimately triggering potent
CD8+ T cell- mediated antitumor effects on syngeneic mouse tumors [124]. The presence of MHC-I and MHC-II molecules, costimulatory molecules and other components on the surface of DEX give them the potential to promote T cells and NK (natural killer) cells mediating tumor rejection responses [125]. In addition, DEX-based phase I and II clinical trials have been carried out in advanced non-small cell lung cancer, colorectal and melanoma, suggested that DEX vaccine was feasible and well tolerated, however, the number of patients is small, thus requiring larger samples and more studies to further verify they efficiency and safety [126129]. Recently, the role of HCC cells-derived exosome in immunotherapy has been explored. Dendritic cells (DCs) were activated by pulsed with HCC cells-derived exosomes (TEXs), particularly, TEXs carry an array of HCC antigens. TEX-pulsed DCs were taken up by HCC cells, which significantly activated $\mathrm{T}$ cell-dependent antitumor immunity in host HCC cells, consequently triggering 
markedly antitumor immune response and improving the tumor microenvironment in host HCC cell [130].

\section{$\mathrm{HCC}$ exosomes and drug resistance}

$\mathrm{HCC}$ is highly resistant to commonly used chemotherapeutic agents, such as sorafenib, 5-fluorouracil (5-FU) and doxorubicin. Recent studies demonstrated that exosomes have an important role in drug resistance by transporting RNAs or proteins. Multidrug-resistant cell Bel/5-FU-derived exosomes delivered miR-32-5p to sensitive Bel7402 cells, and miR-32-5p suppressed its downstream target PTEN and activated the PI3K/Akt pathway in Bel7402 cells, hence inducing multidrug resistance of Bel7402 cells [131]. HCC cells delivered exosomes to the sorafenib sensitive of liver cancer cells, which activated the HGF/ c-Met/Akt signaling and inhibited sorafenib-induced apoptosis of host cells, thereby enhancing sorafenib resistance in liver cancer cells [132]. HCC cells released exosomes to recipient HCC cells, linc-VLDLR, a stressresponsive lncRNA, was increased in recipient $\mathrm{HCC}$ cells, meanwhile, its target ATP-binding cassette, sub-family G member 2 (ABCG2) was also up-regulated, particularly reduced chemotherapy-induced cells death, leading to acquired chemoresistance in recipient cells [133].

\section{Exosomes as nanocarries of anticancer therapies}

Due to exosomes naturally deliver nucleic acids, proteins and lipids to recipient cells, they might act as promising vectors of drugs and biological molecules. Accumulate evidences showed that exosomes as drug delivery systems has unique features, such as low immunogenicity, high biocompatibility, poorly toxic, and cross the blood-brain barrier [94, 134]. Kim MS et al. assessed the feasibility of exosome-based formulation of paclitaxel (PTX) for MDR-related anticancer therapy. They found that incorporation of PTX into exosomes significantly increased PTX cytotoxicity in drug resistant MDCKMDR1 (Pgp+) cells in vitro. Moreover, they demonstrated airway-delivered exosomes have a potent anticancer effect in lewis lung carcinoma (LLC) mouse model [135]. The utility of exosomes as biological vehicles for therapeutic agents has been actively explored in HCC therapies. Adipose tissue-derived mesenchymal stem cells (AMSCs) were transfected with miR-122, and miR-122 was effectively packaged into exosomes. Furthermore, AMSCs delivered exosomes to HCC cells, interestingly, exosomal miR-122 inhibited target gene expression in host HCC cells, thereby increasing the sensitivity of HCC cells to chemotherapeutic agents, such as sorafenib, fluorouracil (5-FU) [136]. After hepatitis C virus E2 envelope glycoprotein (HCV-E2) stimulated mast cells, the level of miRNA-490 was increased in mast cells. Moreover, mast cells transferred miRNA-490 to HCC cells via exosomes, which inhibited the ERK1/2 pathway of host HCC cells, ultimately inhibiting HCC cells metastasis
[137]. Propofol stimulated tumor-associated macrophages to secrete exosomes, more importantly, exosomes were taken up by HCC cells, indeed, miR-142-3p expression was increased and its target RAC1 was significantly down-regulated in host HCC cells, resulting in inhibition of HCC cells growth [138].

\section{Conclusion}

Indeed, exosomes play an improtant role in $\mathrm{HCC}$ cells communication with their microenvironment, and provide fertile soil for the seed, thereby facilitating HCC proliferation and metastasis (Table 2, Fig. 2). Nonetheless, there are many problems remain to be elucidated. How miRNA, IncRNA and proteins are sorted to exosomes, and whether or not exosomes uptake is a cell type specific process need to intensive researches. In experimental research, successfully extracting exosomes from cell culture supernatant is challenging and expensive, which limit the study of exosomes. Importantly, the serum of cancer patients contain plenty of exosomes [139], which is beneficial for investigating exosomes as biomarkers for cancers screening and monitoring. Large sample studies are needed to select those exosomal RNAs and proteins with high specificity and sensitivity. Whether exosomes can regulate adaptive immunity in HCC cells microenvironment need further researches, which may offers potential therapeutic strategies for HCC. In addition, new therapeutic agents can be developed utilizing exosomes as biological vehicles.

\section{Abbreviations}

5-FU: 5-fluorouracil; ABCG2: ATP-binding cassette, sub-family G member 2; AFP: Alpha-fetoprotein; AMSCs: Adipose tissue-derived mesenchymal stem cells; B4GALT3: $\beta$-1,4-galactosyltransferases; CAFs: Cancer-associated fibroblasts; CHB: Chronic hepatitis B; DCs: Dendritic cells; EGFR: Epidermal growth factor receptor; EMT: Epithelial-mesenchymal transition; ESCRT: Endosomal sorting complexes required for transport; FBS: Fetal. bovine serum; HCC: Hepatocellular carcinoma; HCV-E2: epatitis C virus E2 envelope glycoprotein; HLSC: Human adult liver stem cells;

hnRNPH1: Heterogeneous nuclear ribonucleoprotein H1; HUVECs: Human umbilical vein endothelial cells; ILVs: Intraluminal vesicles;

LBPA: Lysobisphosphatidic acid; linc-RoR: Long intergenic noncoding RNA regulator of reprogramming; IncRNAs: Long noncoding RNAs;

MVB: Multivesicular body; NF: Nuclear factor; NTA: Nanoparticle tracking analysis; PD-L1: Programmed-cell death ligand 1; rRNA: Ribosomal RNA; snoRNA: Small nucleolar RNA; snRNA: Small nuclear RNA; TAK1: Transforming growth factor $\beta$ activated kinase-1; TEM: Transmission electron microscopy; TRAIL: Tumour-necrosis-factor-related apoptosis-inducing ligand; tRNAs: Transfer RNAs

\section{Acknowledgements}

We do thank for the support of Natural science foundation of China, Shanghai Municipal Education Commission and Shanghai Education Development Foundation.

\section{Funding}

This study was supported Grants 81472124, 81774291, and 17CG43.

Availability of data and materials Not applicable. 


\section{Authors' contributions}

Yu Y participated in the design and assessed relevant bioinformatics. Chen $\mathrm{R}$ analyzed and interpreted data, and wrote the manuscript. $\mathrm{Xu} X$, Tao $Y$ and Qian Z helped to draft the manuscript. All authors critically read and approved the final manuscript.

\section{Ethics approval and consent to participate} Not relevant.

\section{Consent for publication}

Not relevant.

\section{Competing interests}

The authors declare that they have no competing interests.

\section{Publisher's Note}

Springer Nature remains neutral with regard to jurisdictional claims in published maps and institutional affiliations.

\section{Received: 1 November 2018 Accepted: 26 December 2018} Published online: 07 January 2019

\section{References}

1. Bray F, Ferlay J, Soerjomataram I, Siegel RL, Torre LA, Jemal A. Global cancer statistics 2018: GLOBOCAN estimates of incidence and mortality worldwide for 36 cancers in 185 countries. CA Cancer J Clin. 2008:0:1-31.

2. Gomes MA, Priolli DG, Tralhão JG, Botelho MF. Hepatocellular carcinoma: epidemiology, biology, diagnosis, and therapies. Rev Assoc Med Bras (1992). 2013:59:514-24

3. Pardee AD, Butterfield LH. Immunotherapy of hepatocellular carcinoma: unique challenges and clinical opportunities. Oncoimmunology. 2012;1: 48-55.

4. Kahlert C, Kalluri R. Exosomes in tumor microenvironment influence cance progression and metastasis. J Mol Med (Berl). 2013;91:431-7.

5. Raposo G, Stoorvogel W. Extracellular vesicles: exosomes, microvesicles, and friends. J Cell Biol. 2013;200:373-83.

6. Kalluri R. The biology and function of exosomes in cancer. J Clin Invest. 2016;126:1208-15

7. Johnstone RM, Adam M, Hammond JR, Orr L, Turbide C. Vesicle formation during reticulocyte maturation association of plasma membrane activities with released vesicles (exosomes). J Biol Chem. 1987;262:9412-20.

8. Luzio JP, Gray SR, Bright NA. Endosome-lysosome fusion. Biochem Soc Trans. 2010;38:1413-6.

9. Thery C, Zitvogel L, Amigorena S. Exosomes: composition, biogenesis and function. Nat Rev Immunol. 2002;2:569-79.

10. Mathivanan S, Ji H, Simpson RJ. Exosomes: extracellular organelles important in intercellular communication. J Proteome. 2010;73:1907-20.

11. De Toro J, Herschlik L, Waldner C, Mongini C. Emerging roles of exosomes in normal and pathological conditions: new insights for diagnosis and therapeutic applications. Front Immunol. 2015;6:203.

12. Hurley JH, Hanson PI. Membrane budding and scission by the ESCRT machinery: it's all in the neck. Nat Rev Mol Cell Biol. 2010;11:556-66.

13. Hurley JH. ESCRT complexes and the biogenesis of multivesicular bodies. Curr Opin Cell Biol. 2008;20:4-11.

14. Raiborg C, Stenmark H. The ESCRT machinery in endosomal sorting of ubiquitylated membrane proteins. Nature. 2009;458:445-52.

15. Wollert T, Hurley JH. Molecular mechanism of multivesicular body biogenesis by ESCRT complexes. Nature. 2010;464:864-9.

16. Williams RL, Urbé $\mathrm{S}$. The emerging shape of the ESCRT machinery. Nat Rev Mol Cell Biol. 2007:8:355-68.

17. Katzmann DJ, Babst M, Emr SD. Ubiquitin-dependent sorting into the multivesicular body pathway requires the function of a conserved endosomal protein sorting complex, ESCRT-I. Cell. 2001;106:145-55.

18. Malerød L, Stuffers S, Brech A, Stenmark H. Vps22/EAP30 in ESCRT-II mediates endosomal sorting of growth factor and chemokine receptors destined for lysosomal degradation. Traffic. 2007:8:1617-29.

19. Wollert T, Wunder C, Lippincott-Schwartz J, Hurley JH. Membrane scission by the ESCRT-III complex. Nature. 2009:458:172-7.

20. Trajkovic K, Hsu C, Chiantia S, Rajendran L, Wenzel D, Wieland F, et al. Ceramide triggers budding of exosome vesicles into multivesicular endosomes. Science. 2008;319:1244-7.
21. Ostrowski M, Carmo NB, Krumeich S, Fanget I, Raposo G, Savina A, et al. Rab27a and Rab27b control different steps of the exosome secretion pathway. Nat Cell Biol. 2010;12:19-30.

22. Vanlandingham PA, Ceresa BP. Rab7 regulates late endocytic trafficking downstream of multivesicular body biogenesis and cargo sequestration. J Biol Chem. 2009;284:12110-24

23. Zeigerer A, Gilleron J, Bogorad RL, Marsico G, Nonaka H, Seifert S, et al. Rab5 is necessary for the biogenesis of the endolysosomal system in vivo. Nature 2012:485:465-70.

24. van Niel G, Charrin S, Simoes S, Romao M, Rochin L, Saftig P, et al. The tetraspanin CD63 regulates ESCRT-independent and -dependent endosomal sorting during melanogenesis. Dev Cell. 2011;21:708-21.

25. Simons M, Raposo G. Exosomes-vesicular carriers for intercellular communication. Curr Opin Cell Biol. 2009;21:575-81.

26. Keller S, Sanderson MP, Stoeck A, Altevogt P. Exosomes: from biogenesis and secretion to biological function. Immunol Lett. 2006;107:102-8.

27. Chaput $N$, Thery C. Exosomes: immune properties and potential clinical implementations. Semin Immunopathol. 2011;33:419-40.

28. Record M, Subra C, Silvente-Poirot S, Poirot M. Exosomes as intercellular signalosomes and pharmacological effectors. Biochem Pharmacol. 2011;81: 1171-82.

29. Tian T, Wang $Y$, Wang H, Zhu Z, Xiao Z. Visualizing of the cellular uptake and intracellular trafficking of exosomes by live-cell microscopy. J Cell Biochem. 2010;111:488-96.

30. Feng D, Zhao WL, Ye YY, Bai XC, Liu RQ, Chang LF. Cellular internalization of exosomes occurs through phagocytosis. Traffic. 2010;11:675-87.

31. Tian T, Zhu YL, Zhou YY, Liang GF, Wang YY, Hu FH, et al. Exosome uptake through clathrin-mediated endocytosis and macropinocytosis and mediating miR-21 delivery. J Biol Chem. 2014;289:22258-67.

32. Damke H, Baba T, van der Bliek AM, Schmid SL. Clathrin-independent pinocytosis is induced in cells overexpressing a temperature-sensitive mutant of dynamin. J Cell Biol. 1995:131:69-80.

33. Miyanishi M, Tada K, Koike M, Uchiyama Y, Kitamura T, Nagata S. Identification of Tim4 as a phosphatidylserine receptor. Nature. 2007:450: 435-9.

34. Kowal J, Tkach $M$, Théry C. Biogenesis and secretion of exosomes. Curr Opin Cell Biol. 2014;29:116-25.

35. Colombo M, Raposo G, Théry C. Biogenesis, secretion, and intercellulari interactions of exosomes and other extracellular vesicles. Annu Rev Cell Dev Biol. 2014;30:255-89.

36. Matsuo H, Chevallier J, Mayran N, Le Blanc I, Ferguson C, Fauré J, et al. Role of LBPA and Alix in multivesicular liposome formation and endosome organization. Science. 2004;303:531-4

37. Théry C, Boussac M, Véron P, Ricciardi-Castagnoli P, Raposo G, Garin J et al. Proteomic analysis of dendritic cell-derived exosomes: a secreted subcellular compartment distinct from apoptotic vesicles. J Immunol. 2001:166:7309-18.

38. van Niel G, Porto-Carreiro I, Simoes S, Raposo G. Exosomes: a common pathway for a specialized function. J Biochem. 2006:140:13-21.

39. Escola JM, Kleijmeer MJ, Stoorvogel W, Griffith JM, Yoshie O, Geuze HJ. Selective enrichment of tetraspan proteins on the internal vesicles of multivesicular endosomes and on exosomes secreted by human Blymphocytes. J Biol Chem. 1998;273:20121-7.

40. Vlassov AV, Magdaleno S, Setterquist R, Conrad R. Exosomes: current knowledge of their composition, biological functions, and diagnostic and therapeutic potentials. Biochim Biophys Acta. 2012;1820:940-8.

41. Baietti MF, Zhang Z, Mortier E, Melchior A, Degeest G, Geeraerts A, et al. Syndecan-syntenin-ALIX regulates the biogenesis of exosomes. Nat Cell Biol. 2012;14:677-85

42. Hoshino A, Costa-Silva B, Shen TL, Rodrigues G, Hashimoto A, Tesic Mark M, et al. Tumour exosome integrins determine organotropic metastasis. Nature. 2015:527:329-35.

43. Whiteside TL. Immune modulation of T-cell and NK (natural killer) cell activities by TEXs (tumour-derived exosomes). Biochem Soc Trans. 2013;41: 245-51

44. Baran J, Baj-Krzyworzeka M, Weglarczyk K, Szatanek R, Zembala M, Barbasz J, et al. Circulating tumour-derived microvesicles in plasma of gastric cancer patients. Cancer Immunol Immunother. 2010;59:841-50.

45. Adamczyk KA, Klein-Scory S, Tehrani MM, Warnken U, Schmiegel W, Schnolzer $M$, et al. Characterization of soluble and exosomal forms of the EGFR released from pancreatic cancer cells. Life Sci. 2011;89:304-12. 
46. Valadi H, Ekström K, Bossios A, Sjöstrand M, Lee JJ, Lötvall JO. Exosomemediated transfer of mRNAs and microRNAs is a novel mechanism of genetic exchange between cells. Nat Cell Biol. 2007;9:654-9.

47. Wei Z, Batagov AO, Schinelli S, Wang J, Wang Y, El Fatimy R, et al. Coding and noncoding landscape of extracellular RNA released by human glioma stem cells. Nat Commun. 2017:8:1145

48. Eirin A, Riester SM, Zhu XY, Tang H, Evans JM, O'Brien D, et al. MicroRNA and mRNA cargo of extracellular vesicles from porcine adipose tissuederived mesenchymal stem cells. Gene. 2014;551:55-64.

49. Mittelbrunn M, Gutiérrez-Vázquez C, Villarroya-Beltri C, González S, SánchezCabo F, González MÁ, et al. Unidirectional transfer of microRNA-loaded exosomes from T cells to antigen-presenting cells. Nat Commun. 2011;2:282.

50. Bellingham SA, Coleman BM, Hill AF. Small RNA deep sequencing reveals a distinct miRNA signature released in exosomes from prion-infected neuronal cells. Nucleic Acids Res. 2012;40:10937-49.

51. Huang X, Yuan T, Tschannen M, Sun Z, Jacob H, Du M, et al. Characterization of human plasma-derived exosomal RNAs by deep sequencing. BMC Genomics. 2013;14:319.

52. Gusachenko ON, Zenkova MA, Vlassov W. Nucleic acids in exosomes: disease markers and intercellular communication molecules. Biochemistry (Mosc). 2013;78:1-7.

53. Bullock MD, Silva AM, Kanlikilicer-Unaldi P, Filant J, Rashed MH, Sood AK, et al. Exosomal non-coding RNAs: diagnostic, prognostic and therapeutic applications in cancer. Noncoding RNA. 2015;1:53-68.

54. Belting M, Wittrup A. Nanotubes, exosomes, and nucleic acid -binding peptides provide novel mechanisms of intercellular communication in eukaryotic cells: implications in health and disease. J Cell Biol. 2008;183:1187-91.

55. Cheng L, Sharples RA, Scicluna BJ, Hill AF. Exosomes provide a protective and enriched source of miRNA for biomarker profiling compared to intracellular and cell-free blood. J Extracell Vesicles. 2014;26:3.

56. Balaj L, Lessard R, Dai L, Cho YJ, Pomeroy SL, Breakefield XO, et al. Tumour microvesicles contain retrotransposon elements and amplified oncogene sequences. Nat Commun. 2011;2:180.

57. Thakur BK, Zhang H, Becker A, Matei I, Huang Y, Costa-Silva B, et al. Doublestranded DNA in exosomes: a novel biomarker in cancer detection. Cell Res. 2014:24:766-9.

58. Kahlert C, Melo SA, Protopopov A, Tang J, Seth S, Koch M, et al. Identification of double stranded genomic DNA spanning all chromosomes with mutated KRAS and p53 DNA in the serum exosomes of patients with pancreatic cancer. J Biol Chem. 2014;289:3869-75.

59. Théry C, Amigorena S, Raposo G, Clayton A. Isolation and characterization of exosomes from cell culture supernatants and biological fluids. Curr Protoc Cell Biol. 2006;3:22

60. Staubach S, Razawi H, Hanisch FG. Proteomics of MUC1-containing lipid rafts from plasma membranes and exosomes of human breast carcinoma cells MCF-7C. Proteomics. 2009;9:2820-35.

61. Luga V, Zhang L, Viloria-Petit AM, Ogunjimi AA, Inanlou MR, Chiu E, et al. Exosomes mediate stromal mobilization of autocrine Wnt-PCP signaling in breast cancer cell migration. Cell. 2012;151:1542-56.

62. Subra C, Grand D, Laulagnier K, Stella A, Lambeau G, Paillasse M, et al. Exosomes account for vesicle-mediated transcellular transport of activatable phospholipases and prostaglandins. J Lipid Res. 2010;51:2105-20.

63. Zhang L, Zhang S, Yao J, Lowery FJ, Zhang Q, Huang WC, et al. Microenvironment-induced PTEN loss by exosomal microRNA primes brain metastasis outgrowth. Nature. 2015;527:100-4.

64. Rana S, Malinowska K, Zöller M. Exosomal tumor microRNA modulates premetastatic. Neoplasia. 2013;15:281-95.

65. Liu Y, Gu Y, Han Y, Zhang Q, Jiang Z, Zhang X, et al. Tumor exosomal RNAs promote lung pre-metastatic niche formation by activating alveolar epithelial TLR3 to recruit neutrophils. Cancer Cell. 2016;30:243-56.

66. Squadrito ML, Baer C, Burdet F, Maderna C, Gilfillan GD, Lyle R, et al. Endogenous RNAs modulate microRNA sorting to exosomes and transfer to acceptor cells. Cell Rep. 2014:8:1432-46.

67. Cho JA, Park H, Lim EH, Lee KW. Exosomes from breast cancer cells can convert adipose tissue derived mesenchymal stem cells into myofibroblastlike cells. Int J Oncol. 2012;40:130-8.

68. Hood JL, San RS, Wickline SA. Exosomes released by melanoma cells prepare sentinel lymph nodes for tumor metastasis. Cancer Res. 2011;71:3792-801.

69. Shao H, Im H, Castro CM, Breakefield X, Weissleder R, Lee H. New technologies for analysis of extracellular vesicles. Chem Rev. 2018;1 18:1917-50.
70. Smyth T, Kullberg M, Malik N, Smith-Jones P, Graner MW, Anchordoquy TJ. Biodistribution and delivery efficiency of unmodified tumor-derived exosomes. J Control Release. 2015;199:145-55.

71. Webber JP, Spary LK, Sanders AJ, Chowdhury R, Jiang WG, Steadman R, et al. Differentiation of tumour-promoting stromal myofibroblasts by cancer exosomes. Oncogene. 2015:34:290-302.

72. Cho JA, Park H, Lim EH, Kim KH, Choi JS, Lee JH, et al. Exosomes from ovarian cancer cells induce adipose tissue-derived mesenchymal stem cells to acquire the physical and functional characteristics of tumor-supporting myofibroblasts. Gynecol Oncol. 2011;123:379-86.

73. Lobb RJ, Becker M, Wen SW, Wong CS, Wiegmans AP, Leimgruber A, et al. Optimized exosome isolation protocol for cell culture supernatant and human plasma. J Extracell Vesicles. 2015;4:27031.

74. Van Deun J, Mestdagh P, Sormunen R, Cocquyt V, Vermaelen K, Vandesompele $J$, et al. The impact of disparate isolation methods for extracellular vesicles on downstream RNA profiling. J Extracell Vesicles. 2014;3:24858.

75. Clayton A, Court J, Navabi H, Adams M, Mason MD, Hobot JA, et al. Analysis of antigen presenting cell derived exosomes, based on immuno-magnetic isolation and flow cytometry. J Immunol Methods. 2001:247:163-74.

76. Wubbolts R, Leckie RS, Veenhuizen PT, Schwarzmann G, Möbius W, Hoernschemeyer J, et al. Proteomic and biochemical analyses of human B cell-derived exosomes. J Biol Chem. 2003;278:10963-72.

77. Tauro BJ, Greening DW, Mathias RA, Ji H, Mathivanan S, Scott AM, et al. Comparison of ultracentrifugation, density gradient separation, and immunoaffinity capture methods for isolating human colon cancer cell line LIM1863-derived exosomes. Methods. 2012;56:293-304.

78. Momen-Heravi F, Balaj L, Alian S, Mantel PY, Halleck AE, Trachtenberg AJ, et al. Current methods for the isolation of extracellular vesicles. Biol Chem. 2013;394:1253-62

79. Caradec J, Kharmate G, Hosseini-Beheshti E, Adomat H, Gleave M, Guns E. Reproducibility and efficiency of serum-derived exosome extraction methods. Clin Biochem. 2014:47:1286-92.

80. Kalra H, Adda CG, Liem M, Ang CS, Mechler A, Simpson RJ, et al. Comparative proteomics evaluation of plasma exosome isolation techniques and assessment of the stability of exosomes in normal human blood plasma. Proteomics. 2013:13:3354-64.

81. Au Yeung CL, Co NN, Tsuruga T, Yeung TL, Kwan SY, Leung CS, et al. Exosomal transfer of stroma-derived miR21 confers paclitaxel resistance in ovarian cancer cells through targeting APAF1. Nat Commun. 2016;7:11150.

82. Qu L, Ding J, Chen C, Wu ZJ, Liu B, Gao Y, et al. Exosome-transmitted IncARSR promotes sunitinib resistance in renal cancer by acting as a competing endogenous RNA. Cancer Cell. 2016;29:653-68.

83. Sokolova V, Ludwig AK, Hornung S, Rotan O, Horn PA, Epple M, et al. Characterisation of exosomes derived from human cells by nanoparticle tracking analysis and scanning electron microscopy. Colloids Surf B Biointerfaces. 2011;87:146-50.

84. Lasser C, Alikhani VS, Ekstrom K, Eldh M, Paredes PT, Bossios A, et al. Human saliva, plasma and breast milk exosomes contain RNA: uptake by macrophages. J Transl Med. 2011;9:9.

85. Vella LJ, Greenwood DL, Cappai R, Scheerlinck JP, Hill AF. Enrichment of prion protein in exosomes derived from ovine cerebral spinal fluid. Vet Immunol Immunopathol. 2008;124:385-93.

86. Caby MP, Lankar D, Vincendeau-Scherrer C, Raposo G, Bonnerot C. Exosomal-like vesicles are present in human blood plasma. Int Immunol. 2005;17:879-87.

87. Pisitkun T, Shen RF, Knepper MA. Identification and proteomic profiling of exosomes in human urine. PNAS. 2004;101:13368-73.

88. Runz S, Keller S, Rupp C, Stoeck A, Issa Y, Koensgen D, et al. Malignant ascites-derived exosomes of ovarian carcinoma patients contain CD24 and EpCAM. Gynecol Oncol. 2007;107:563-71.

89. Bard MP, Hegmans JP, Hemmes A, Luider TM, Willemsen R, Severijnen LA, et al. Proteomic analysis of exosomes isolated from human malignant pleural effusions. Am J Respir Cell Mol Biol. 2004;31:114-21.

90. Rodriguez M, Silva J, Lopez-Alfonso A, Lopez-Muniz MB, Pena C, Dominguez $\mathrm{G}$, et al. Different exosome cargo from plasma/ bronchoalveolar lavage in non-small-cell lung cancer. Genes Chromosomes Cancer. 2014:53:713-24.

91. Azmi AS, Bao B, Sarkar FH. Exosomes in cancer development, metastasis, and drug resistance: a comprehensive review. Cancer Metastasis Rev. 2013;32:623-42.

92. Dear JW, Street JM, Bailey MA. Urinary exosomes: a reservoir for biomarker discovery and potential mediators of intrarenal signalling. Proteomics.2013; 13:1572-80. 
93. Syn N, Wang L, Sethi G, Thiery JP, Goh BC. Exosome-mediated metastasis: from epithelial-mesenchymal transition to escape from immunosurveillance. Trends Pharmacol Sci. 2016;37:606-17.

94. Syn NL, Wang L, Chow EK, Lim CT, Goh BC. Exosomes in cancer nanomedicine and immunotherapy: prospects and challenges. Trends Biotechnol. 2017:35:665-76

95. Li X, Wang Y, Wang Q, Liu Y, Bao W, Wu S. Exosomes in cancer: small transporters with big functions. Cancer Lett. 2018;435:55-65.

96. Xu H, Dong X, Chen Y, Wang X. Serum exosomal hnRNPH1 mRNA as a novel marker for hepatocellular carcinoma. Clin Chem Lab Med. 2017;56:1-6.

97. Sugimachi K, Matsumura T, Hirata H, Uchi R, Ueda M, Ueo H, et al. Identification of a bona fide microRNA biomarker in serum exosomes that predicts hepatocellular carcinoma recurrence after liver transplantation. $\mathrm{Br}$ J Cancer. 2015;112:532-8.

98. Wang H, Hou L, Li A, Duan Y, Gao H, Song X. Expression of serum exosomal microRNA-21 in human hepatocellular carcinoma. Biomed Res Int. 2014; 2014:864894.

99. Sohn W, Kim J, Kang SH, Yang SR, Cho JY, Cho HC, et al. Serum exosomal microRNAs as novel biomarkers for hepatocellular carcinoma. Exp Mol Med. 2015;47:e184.

100. Liu W, Hu J, Zhou K, Chen F, Wang Z, Liao B, et al. Serum exosomal miR$125 \mathrm{~b}$ is a novel prognostic marker for hepatocellular carcinoma. Onco Targets Ther. 2017;10:3843-51.

101. Wang Y, Zhang C, Zhang P, Guo G, Jiang T, Zhao X, et al. Serum exosomal microRNAs combined with alpha-fetoprotein as diagnostic markers of hepatocellular carcinoma. Cancer Med. 2017;7:1670-9.

102. Zhang C, Yang X, Qi Q, Gao Y, Wei Q, Han S. IncRNA-HEIH in serum and exosomes as a potential biomarker in the HCV-related hepatocellular carcinoma. Cancer Biomark. 2018;21:651-9.

103. $X u$ H, Chen $Y$, Dong $X$, Wang $X$. Serum exosomal long noncoding RNAs ENSG00000258332.1 and LINC00635 for the diagnosis and prognosis of hepatocellular carcinoma. Cancer Epidemiol Biomark Prev. 2018;27:710-6.

104. Kogure T, Lin WL, Yan IK, Braconi C, Patel T. Inter-cellular nanovesicle mediated microRNA transfer: a mechanism of environmental modulation of hepatocellular cancer cell growth. Hepatology. 2011;54:1237-48.

105. Wang S, Xu M, Li X, Su X, Xiao X, Keating A. Exosomes released by hepatocarcinoma cells endow adipocytes with tumor-promoting properties. J Hematol Oncol. 2011:11:82.

106. He M, Qin H, Poon TC, Sze SC, Ding X, Co NN, et al. Hepatocellular carcinomaderived exosomes promote motility of immortalized hepatocyte through transfer of oncogenic proteins and RNAs. Carcinogenesis. 2015;36:1008-18.

107. Conigliaro A, Costa V, Lo Dico A, Saieva L, Buccheri S, Dieli F, et al. CD90+ liver cancer cells modulate endothelial cell phenotype through the release of exosomes containing H19 IncRNA. Mol Cancer. 2015;14:155.

108. Huang A, Dong J, Li S, Wang C, Ding H, Li H, et al. Exosomal transfer of vasorin expressed in hepatocellular carcinoma cells promotes migration of human umbilical vein endothelial cells. Int J Biol Sci. 2015;11:961-9.

109. Blackwell RH, Foreman KE, Gupta GN. The role of cancer-derived exosomes intumorigenicity \& epithelial-to-mesenchymal transition. Cancers (Basel). 2017;9:E105

110. Vella LJ. The emerging role of exosomes in epithelial-mesenchymaltransition in cancer. Front Oncol. 2014;4:361.

111. Greening DW, Gopal SK, Mathias RA, Liu L, Sheng J, Zhu HJ, et al. Emerging roles of exosomes during epithelial-mesenchymaltransition and cancer progression. Semin Cell Dev Biol. 2015;40:60-71.

112. Chen L, Guo P, He Y, Chen Z, Chen L, Luo Y, et al. HCC-derived exosomes elicit HCC progression and recurrence by epithelial mesenchymal transition through MAPK/ERK signalling pathway. Cell Death Dis. 2018;9:513.

113. Bhowmick NA, Neilson EG, Moses HL. Stromal fibroblasts in cancer initiation and progression. Nature. 2004;432:332-7.

114. Fang T, LV H, LV G, Li T, Wang C, Han Q, et al. Tumor-derived exosomal miR1247-3p induces cancer-associated fibroblast activation to foster lung metastasis of liver cancer. Nat Commun. 2018;9:191.

115. Basu S, Bhattacharyya SN. Insulin-like growth factor-1 prevents miR-122 production in neighbouring cells to curtail its intercellular transfer to ensure proliferation of human hepatoma cells. Nucleic Acids Res. 2014;42:7170-85.

116. Kogure T, Yan IK, Lin WL, Patel T. Extracellular vesicle-mediated transfer of a novel long noncoding RNA TUC339: a mechanism of intercellular signaling in human hepatocellular cancer. Genes Cancer. 2013;4:261-72.

117. Takahashi K, Yan IK, Haga H, Patel T. Modulation of hypoxia-signaling pathways by extracellular linc-RoR. J Cell Sci. 2014;127:1585-94.
118. Zhang Z, Li X, Sun W, Yue S, Yang J, Li J, et al. Loss of exosomal miR-320a from cancer-associated fibroblasts contributes to HCC proliferation and metastasis. Cancer Lett. 2017;397:33-42.

119. Wang F, Li L, Piontek K, Sakaguchi M, Selaru FM. Exosome-miR-335 as a novel therapeutic strategy in hepatocellular carcinoma. Hepatology. 2018;67: 940-54.

120. Fonsato V, Collino F, Herrera MB, Cavallari C, Deregibus MC, Cisterna B, et al. Human liver stem cell-derived microvesicles inhibit hepatoma growth in SCID mice by delivering antitumor microRNAs. Stem Cells. 2012;30:1985-98.

121. Wang S, Chen G, Lin X, Xing X, Cai Z, Liu X, et al. Role of exosomes in hepatocellular carcinoma cell mobility alteration. Oncol Lett. 2017;14:8122-31.

122. Fang JH, Zhang ZJ, Shang LR, Luo YW, Lin YF, Yuan Y, et al. Hepatoma cellsecreted exosomal microRNA-103 increases vascular permeability and promotes metastasis by targeting junction proteins. Hepatology. 2018;68: 1459-75.

123. Li B, Mao R, Liu C, Zhang W, Tang Y, Guo Z. LncRNA FAL1 promotes cell proliferation and migration by acting as a ceRNA of miR-1236 in hepatocellular carcinoma cells. Life Sci. 2018;197:122-9.

124. Wolfers J, Lozier A, Raposo G, Regnault A, Théry C, Masurier C, et al. Tumorderived exosomes are a source of shared tumor rejection antigens for CTL cross-priming. Nat Med. 2001;7:297-303.

125. Pitt JM, André F, Amigorena S, Soria JC, Eggermont A, Kroemer G, et al. Dendritic cell-derived exosomes for cancer therapy. J Clin Invest. 2016;126: 1224-32.

126. Besse B, Charrier M, Lapierre V, Dansin E, Lantz O, Planchard D, et al. Dendritic cell-derived exosomes as maintenance immunotherapy after first line chemotherapy in NSCLC. Oncoimmunology. 2016;5:e1071008.

127. Morse MA, Garst J, Osada T, Khan S, Hobeika A, Clay TM, et al. A phase I study of dexosome immunotherapy in patients with advanced non-small cell lung cancer. J Transl Med. 2005;3:9.

128. Dai S, Wei D, Wu Z, Zhou X, Wei X, Huang H, et al. Phase I clinical trial of autologous ascites-derived exosomes combined with GM-CSF for colorectal cancer. Mol Ther. 2008;16:782-90.

129. Escudier B, Dorval T, Chaput N, André F, Caby MP, Novault S, et al. Vaccination of metastatic melanoma patients with autologous dendritic cell (DC) derived-exosomes: results of the first phase I clinical trial. J Transl Med. 2005;3:10.

130. Rao Q, Zuo B, Lu Z, Gao X, You A, Wu C, et al. Tumor-derived exosomes elicit tumor suppression in murine hepatocellular carcinoma models and humans in vitro. Hepatology. 2016;64:456-72.

131. Fu X, Liu M, Qu S, Ma J, Zhang Y, Shi T, et al. Exosomal microRNA-32-5p induces multidrug resistance in hepatocellular carcinoma via the PI3K/Akt pathway. J Exp Clin Cancer Res. 2018;37:52.

132. Qu Z, Wu J, Wu J, Luo D, Jiang C, Ding Y. Exosomes derived from HCC cells induce sorafenib resistance in hepatocellular carcinoma both in vivo and in vitro. J Exp Clin Cancer Res. 2016:35:159.

133. Takahashi K, Yan IK, Wood J, Haga H, Patel T. Involvement of extracellular vesicle long noncoding RNA (linc-VLDLR) in tumor cell responses to chemotherapy. Mol Cancer Res. 2014;12:1377-87.

134. Ha D, Yang N, Nadithe V. Exosomes as therapeutic drug carriers and delivery vehicles across biological membranes: current perspectives and future challenges. Acta Pharm Sin B. 2016;6:287-96.

135. Kim MS, Haney MJ, Zhao Y, Mahajan V, Deygen I, Klyachko NL, et al. Development of exosome-encapsulated paclitaxel to overcome MDR in cancer cells. Nanomedicine. 2016;12:655-64.

136. Lou G, Song X, Yang F, Wu S, Wang J, Chen Z, et al. Exosomes derived from miR-122-modified adipose tissue-derived MSCs increase chemosensitivity of hepatocellular carcinoma. J Hematol Oncol. 2015;8:122.

137. Xiong L, Zhen S, Yu Q, Gong Z. HCV-E2 inhibits hepatocellular carcinoma metastasis by stimulating mast cells to secrete exosomal shuttle microRNAs. Oncol Lett. 2017:14:2141-6.

138. Zhang J, Shan WF, Jin TT, Wu GQ, Xiong XX, Jin HY, et al. Propofol exerts anti-hepatocellular carcinoma by microvesicle-mediated transfer of miR-1423p from macrophage to cancer cells. J Transl Med. 2014;12:279.

139. Melo SA, Sugimoto H, O'Connell JT, Kato N, Villanueva A, Vidal A, et al. Cancer exosomes perform cell-independent microRNA biogenesis and promote tumorigenesis. Cancer Cell. 2014;26:707-21. 